\title{
Medicolegal
}

\section{What should a doctor tell?}

\author{
BY OUR LEGAL CORRESPONDENT
}

Fears of a flood of malpractice claims and widespread "defensive doctoring" have been averted by a decision by the House of Lords. They decisively rejected the legal theory, American in origin, which goes under the potentially misleading label of "informed consent." All the members of the House of Lords agreed that the plaintiff failed in her claim on the facts whatever choice was made between the submissions as to the law; but they added guidance on the law, not all to the same effect.

\section{Facts of the case}

Mrs Amy Sidaway brought an action for damages in respect of personal injuries suffered as a result of a surgical operation in October 1974. The injuries were serious and the damages were agreed, subject to liability, at $£ 67500$.

The operation was performed by a neurosurgeon, the late $\mathrm{Mr}$ Murray Falconer, who died in August 1977. The defendants to the action were the governing body of the Maudsley Hospital and the executors of $\mathrm{Mr}$ Falconer. On appeal there was no challenge to the judge's findings: that Mr Falconer's diagnosis was correct; that his recommendation in favour of operative treatment was one which he could reasonably and properly have made to his patient; and that he performed the operation with due care and skill.

The complaint made by the plaintiff was that $\mathrm{Mr}$ Falconer was in breach of his duty as her medical adviser in failing to warn her of the risk of damage to the spinal cord.

The medical witnesses had differing views as to what they would have said to their patient in the circumstances, but they were all agreed that a decision not to warn her of the danger of damage to the spinal cord and of its possible consequences was in accordance with a practice accepted as proper by a responsible body of opinion among neurosurgeons. The case therefore raised the question whether the law requires doctors to go further than act in accordance with such accepted practice in warning of dangers.

The trial judge did not accept Mrs Sidaway's evidence that $\mathrm{Mr}$ Falconer gave no warning. Since Mr Falconer had died before trial there was no other direct evidence of what was said, but the judge made some findings based on Mr Falconer's known usual practice.

Lord Scarman set out the facts as follows: "Mrs Sidaway was 71 years of age at the time of the trial in 1982. She was severely disabled by a partial paralysis resulting from her operation. The relationship of doctor and patient between $\mathrm{Mr}$ Falconer and herself had been longstanding before the operation. In 1958 she had injured an elbow at work and as a result had suffered persistent pain. Treatment failed to relieve pain. In July 1960 she was referred to the Maudsley Hospital, where Mr Falconer discovered that the second and third cervical vertebrae were congenitally fused and that there was a significant narrowing of the spinal column between the fifth and sixth vertebrae. Mr Falconer diagnosed the deformity in this area as the cause of her pain. He decided to operate. He removed the disc between the fifth and sixth vertebrae of the neck and fused the two vertebrae by a bone graft. Although pain persisted for another two years, it eventually disappeared. Mr Falconer's diagnosis was proved correct, and his operation ultimately succeeded in relieving his patient's pain.
“Mr Falconer annually reviewed his patient's progress between 1960 and 1970. In 1973 he wrote to Mrs Sidaway asking how she was. She replied complaining of very persistent pain "in the right arm and shoulder," which was the same area as before, and now also of pain in the left forearm. Mr Falconer saw her in the early months of 1974. After some delays she was admitted to hospital on 11 October 1974. Her pain in the meantime had got progressively worse.

"On admission Mrs Sidaway was examined by Dr Goudarzi, a junior member of $\mathrm{Mr}$ Falconer's team. On 17 October she underwent a myelogram, which disclosed a partial block at the level of the $C 4 / 5$ disc space, a posterior ridge in the same area which appeared to have, at least in part, a bony structure, and a narrowing of the subarachnoid space in the same area. Mr Falconer diagnosed that pressure on a nerve root was the cause of her pain and decided to operate."

The operation consisted of a laminectomy of the fourth cervical vertebra and facetectomy or foraminectomy of the disc space between the fourth and fifth cervical vertebrae. At the operation, Mr Falconer freed the fourth cervical nerve root by removing the facets from the fourth vertebra and used a dental drill to free the nerve within the foramen.

Lord Scarman commented: "It was common ground between all the neurosurgeons who gave evidence that the operation involved specific risks beyond those inherent in all operations under general anaesthetic. So far as the general risks are concerned the judge commented that Mrs Sidaway was a healthy woman apart from her cervical spine, and no medical witness had suggested that any special warning as to the existence of those risks needed to be given.

"The two specific risks of injury were: damage to a nerve root in the area of operation and damage to the spinal cord either by direct contact or by some interference, which might be slight and of short duration or very much more serious, of the radicular arteries running through a foramen.

"The risk of either sort of damage was not great: one surgeon estimated the degree of risk at between $1 \%$ and $2 \%$. But if either risk materialised the injury could be severe. Mr Uttley, the distinguished surgeon called on behalf of Mrs Sidaway, said that the possible effects of the damage ranged from a sensation of pins and needles in the hand to a partial paralysis. All the surgeons who were called as expert witnesses accepted that the risk of damage, though slight, was a real one. They distinguished between the two categories of specific risk, the effect of damage to a nerve root being in all probability that the operation would fail to relieve and might increase pain, while damage to the spinal cord might cause a partial paralysis. The risk of damage to the spinal cord was, however, in their opinion less than $1 \%$."

\section{Consent}

When Mrs Sidaway signed the usual consent form Dr Goudarzi explained the nature and purpose of the operation, but he left the warning of the risks to Mr Falconer. Hospital records showed that Mr Falconer saw Mrs Sidaway the day before the operation. The 
trial judge inferred from Mr Falconer's usual practice that it was probable that he mentioned the possibility of disturbing a nerve root and the consequences of doing so but did not refer to the danger of cord damage or to the fact that this was an elective operation.

The expert witnesses agreed that they would have given some warning of the specific risks. They would have explained the nature and purpose of the operation and that there was a small risk of untoward consequences and of an increase in pain instead of relief. $\mathrm{Mr}$ Uttley would in addition have warned of the possible risk of some resultant weakness in the legs. But he would not question the judgment of a surgeon that it was not in the patient's interests to frighten her by talking about death or paralysis and agreed that such a judgment would be in keeping with a practice accepted as proper by a responsible body of competent neurosurgeons. The other medical witnesses agreed that such a practice existed.

Mrs Sidaway said that had the risks been explained to her fully she would not have consented to the operation.

\section{Legal disagreement}

All the members of the House of Lords agreed in dismissing the plaintiff's appeal, but Lord Scarman dissented on the law. The majority held that the doctor's duty to advise and warn the patient of risks was to be judged by the same test as his duty in diagnosis and treatment. The test applied is known as the "Bolam test": in Bolam $v$ Friern Barnet Hospital Management Committee the judge directed a jury as to the standard of care required of a doctor as follows: "The test is the standard of the ordinary skilled man exercising and professing to have that special skill. ... It is sufficient if he exercises the ordinary skill of an ordinary competent man exercising that particular art."

Someone holding himself out as a specialist must show greater skill than a general practitioner. But the Bolam test accepts that a doctor is not negligent if he acts in accordance with a practice accepted at the time as proper by a responsible body of medical opinion, even though other doctors adopt a different practice. The Bolam test was not new when formulated in 1957 and has since been applied by the House of Lords to diagnosis ${ }^{3}$ and treatment. ${ }^{4}$ It has now, in Sidaway, been applied to the duty to warn.

Lord Diplock said that if a patient put questions the doctor would answer whatever the patient wanted to know, but Mrs Sidaway's complaint was that information had not been volunteered.

"To decide what risks the existence of which a patient should be voluntarily warned and the terms in which such warning, if any, should be given, having regard to the effect that the warning may have, is as much an exercise of professional skill and judgment as any other part of the doctor's comprehensive duty of care to the individual patient," he said, adding "expert medical evidence on this matter should be treated in just the same way. The Bolam test should be applied."

Lord Bridge (with whom Lord Keith agreed) gave reasons to a similar effect but added a proviso giving the court the power in extreme cases to overrule accepted medical opinion: "But even in a case where, as here, no expert witness in the relevant medical field condemns the non-disclosure as being in conflict with accepted and responsible medical practice, I am of opinion that the judge might in certain circumstances come to the conclusion that disclosure of a particular risk was so obviously necessary to an informed choice on the part of the patient that no reasonably prudent medical man would fail to make it. The kind of case I have in mind would be an operation involving a substantial risk of grave adverse consequences, as, for example, the $10 \%$ risk of a stroke from the operation which was the subject of the Canadian case of Reibl $v$ Hughes. In such a case, in the absence of some cogent clinical reason why the patient should not be informed, a doctor, recognising and respecting his patient's right of decision could hardly fail to appreciate the necessity for an appropriate warning."

The fifth Law Lord, Lord Templeman, gave reasons which were inconsistent with the "informed consent" defence but which did not expressly adopt or refer to the Bolam test. He said, "I do not subscribe to the theory that the patient is entitled to know everything nor to the theory that the doctor is entitled to decide everything. . . . If the doctor making a balanced judgment advises the patient to submit to the operation the patient is entitled to reject that advice for reasons which are rational, or irrational, or for no reason. The duty of the doctor in these circumstances, subject to his overriding duty to have regard to the best interests of the patient, is to provide the patient with information which will enable the patient to make a balanced judgment if the patient chooses to make a balanced judgment. A patient may make an unbalanced judgment because he is deprived of adequate information. A patient may also make an unbalanced judgment if he is provided with too much information and is made aware of possibilities which he is not capable of assessing because of his lack of medical training, his prejudices, or his personality. Thus the provision of too much information may prejudice the attainment of the objective of restoring the patient's health.

In order to make a balanced judgment if he chooses to do so the patient needs to be aware of the general dangers and of any special dangers in each case without exaggeration or concealment. At the end of the day, the doctor, bearing in mind the best interests of the patient and bearing in mind the patient's right to information which will enable the patient to make a balanced judgment must decide what information should be given to the patient and in what terms that information should be couched. The court will award damages against the doctor if the court is satisfied that the doctor blundered and that the patient was deprived of information which was necessary for the purposes I have outlined."

\section{References \\ 1 Sidaway $v$ Bethlem Royal Hospital and the Maudsley Hospital Health Authority and others February 21, 1985 \\ 2 [1957] 1WLR 582. \\ 3 Maynard $v$ West Midland Regional Health Authority [1984] 1WLR 634 \\ 4 Whitehouse $v$ Jordan [1981] IWLR 246 \\ 5 (1980) $114 \operatorname{DLR}(3 d) 1$}

A middle aged woman who spent three hours a day in front of the screen of a word processor developed a facial rash after several months. The problem cleared when she ceased work, only to recur when work was resumed. The provision of an earthed antistatic mat beneath her chair seemed to help. Otherpeople working with the same apparatus were unaffected. Might this tenuous association be real? If so what is the remedy?

A few reports have been published describing facial rashes in visual display unit operators. The manifestations varied from itching and parasthesiae to erythema and, occasionally, more substantial eruptions; they usually had a rosacea like distribution. ' Static electricity on carpeting and visual display unit screens, low atmospheric humidity, high environmental dust concentrations, and psychological factors have been postulated as causative agents, but because of the few cases reported no definite association has been shown. There is circumstantial evidence that static electricity may be important in the aetiology of such rashes. Most of the reported cases resolved when office carpeting received antistatic treatment, ${ }^{1}$ and it is known that employees in large offices may accumulate strong electrostatic charges. ${ }^{2}$ This may explain the apparent success of the antistatic mat described by the inquirer. The Health and Safety Executive recommends that office carpeting should have antistatic properties, and that the relative humidity should not fall below $40 \% .^{3}$ VDU screens can be treated with an antistatic coating. Adequate ventilation will dissipate heat and dust. Attention should be paid to the ergonomic aspects of the working environment.-W R LEE, professor of occupational medicine, Manchester.

1 Jjønn HH. Report of facial rashes amongst VDU operators in Norway. In: Pearce BG, ed. Health hazards of visual display terminals. London: John Wiley, 1984:17-23.

2 Lee WR. Little shocks. The Practitioner 1981;225:1679-83.

3 Health and Safety Executive. Visual display units. London: HMSO;1983. 